${ }^{6}$ Bartter, F C, and Schwartz, W B, American fournal of Medicine, 1967, 42, 790.

7 Thomas, T H, et al, Lancet, 1978, 1, 621.

${ }^{8}$ Moran, W H, et al, Surgery, 1964, 56, 99.

${ }^{9}$ Dyball, R E J, Fournal of Physiology, 1975, 245, $119 \mathrm{P}$.

${ }^{10}$ Kendler, K S, Weitzman, R E, and Fisher, D A, Clinical Endocrinology, 1978, 8, 89.

${ }_{11}$ Monson, J P, and Richards, P, British Medical fournal, 1978, 1, 24.

12 Delin, K, Aurell, M, and Ewald, J, British Medical fournal, 1978, 1, 757

13 British Medical fournal, 1977, 1, 1050.

\section{The nulliparous patient, the IUD, and subsequent fertility}

At the start of the rekindling of interest in intrauterine devices (IUDs) in the 1950s their use was generally confined to multiparous, older women, and nulliparous, younger women were usually advised to find an alternative means of contraception. Attempts were soon made, however, to design an IUD suitable for use by the young and childless woman. The accent was on finding a device which could be fitted without injuring the relatively tight cervical canal of the nulliparous woman. This problem has been reduced (but not entirely overcome) with the development of narrow-gauge IUD inserters, and the fitting of IUDs in nulliparous women has now become commonplace.

Nevertheless, the use of IUDs in this population has never been totally accepted, and recent publications have once again questioned its advisability. The causes for concern are not the problems associated with the fitting of the IUD-although these are not denied-but the longer-term consequences. These include a possible raised incidence of pregnancy, of expulsion of the device, and of bleeding or pain among nulliparous women when compared with parous women ${ }^{1}$; a raised incidence of pelvic inflammatory disease ${ }^{2}$; and the difficulties of administering an efficient IUD service among these women. ${ }^{3}$

After reviewing data collected from 20000 IUD users in Britain Snowden et al $^{3}$ suggested that the IUD should not be the first choice for nulliparous patients, in whom the doctor should seriously consider alternative methods of contraception. They argued that (in addition to the points raised above) if a nulliparous woman abandons the use of an IUD owing to unacceptable side effects her experience may discourage her from trying it again when her family is complete-the time at which the IUD may be the most suitable contraceptive for many women.

The most serious doubt about the use of the IUD is that it may impair ability to conceive or complete a subsequent pregnancy. The evidence we have suggests that in most cases the ability to conceive after wearing an IUD is not unduly retarded ${ }^{4}$ but the same cannot be said for women who have had pelvic infection, spontaneous abortion, or ectopic pregnancy.

The link between the use of the IUD and pelvic inflammatory disease is undoubted, ${ }^{6-8}$ but the problems of diagnosis and reporting have repeatedly thwarted attempts to establish the incidence with any accuracy. Despite these difficulties, Westrom et $a l^{2}$ have shown that women wearing an IUD had a threefold increase in the rate of salpingitis when compared with other women and that, when controlled for parity, the increase among nulliparous IUD users was seven times that of nulliparous non-IUD users.

What makes these findings the more worrying is the apparent relation between pelvic infection and subsequent infertility. ${ }^{9}$ Furthermore, when pregnancy does occur the proportion who miscarry or who have an ectopic pregnancy is higher among IUD users than among non-IUD users. ${ }^{10-12}$ The effect of pelvic infection, spontaneous abortion, and ectopic pregnancy on the outcome of subsequent (possibly wanted) pregnancies is a matter of especial concern to those who are using an IUD as a means of delaying their first pregnancy.
At present we cannot categorically state that nulliparous women should discontinue the use of the IUD, but sufficient doubt has been raised to suggest the need for a prospective study designed to examine its effects in some detail-a call we made in $1976 .{ }^{13}$ Now, as then, we need a controlled prospective study among adequate numbers of nulliparous womenpreferably including a substantial proportion (of toth past users and non-users of IUDs) with a previous diagnosis of pelvic infection. If the main cause of illness among IUD users is associated with infection and if pelvic infection affects subsequent fertility, then such a study among nulliparous women is overdue.

${ }^{1}$ Weiner, E, Berg, A A, and Johansson, I, British fournal of Obstetrics and Gynaecology, 1978, 85, 204.

${ }^{2}$ Westrom, L, Bengtsson, L P, and Mardh, P, Lancet, 1976, 2, 221.

${ }^{3}$ Snowden, R, Williams, $\mathrm{M}$, and Hawkins, D, The IUD-A Practical Guide. London, Croom Helm, 1977.

4 Tietze, C, and Lewit, S, Studies in Family Planning, 1970, No 55, 1.

Vessey, M P, et al, British Medical fournal, 1978, 1, 265.

6 Targum, S D, and Wright, N H, American fournal of Epidemiology, 1974, 100, 262.

' Faulkner, W L, and Ory, H W, fournal of the American Medical Association, 1976, 235, 1851.

${ }^{8}$ Vessey, M P, et al, fournal of Biosocial Science, 1976, 8, 373.

9 Westrom, L, American fournal of Obstetrics and Gynecology, 1975, 121, 707.

10 Tatum, H J, and Schmidt, F H, Fertility and Sterility, 1977, 28, 407.

${ }^{11}$ Snowden, R, Family Planning Association Medical Newsletter, 1976, 59, 1.

12 Beral, V, British Fournal of Obstetrics and Gynaecology, 1975, 82, 775.

${ }^{13}$ British Medical fournal, 1976, 2, 77.

\section{Children's Joint Committee}

The report ${ }^{1}$ of the Committee on Child Health Services (the Court Report) was published in December 1976. It was widely discussed throughout 1977, but unfortunately most of the argument was concerned with the functions and status of various professional groups rather than with the need to improve services provided for children. The Government's recommendations, which followed these discussions, were published in January 1978 and proved disappointing; for while the DHSS claimed to accept the overall philosophy of the Court Report it agreed to few of the specific measures that had been recommended. Perhaps the blame, if blame there is, should be widely shared. The Court Report was the outcome of a painstaking study of the history and current position of the child health services and provided an imaginative and far-reaching strategy to improve them-but it emphasised that the reorganisation it proposed might take 15-20 years.

Possibly the Court Report would not have aroused such a strong negative reaction among professional groups if its conclusions had concentrated more on principles and less on changes in status (general practitioner paediatricians, consultant community paediatricians, and child health visitors). The negative reactions were compounded by the chronic lack of finance and may explain the Government's meagre responsebut the fact remains that our child health services cannot match the exciting improvements in many other European countries.

One recommendation now implemented is the formation of a children's joint committee. The Court Report stated, "It is our belief that children have special needs which they cannot articulate for themselves and that society has therefore a duty to ensure that these are identified and cogently represented." It therefore recommended that a committee should be set up to give advice directly to the Secretary of State for Health and Social Services. To be effective such a committee needs to be small, with membership based on ability rather than representing sectional interests. These requirements are fulfilled by the composition of the new Children's Joint Committee (the names of the members

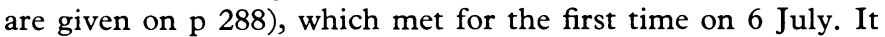


will advise the Secretary of State for Health and Social Services and the Secretary of State for Wales on co-ordinating and developing health and personal social services as they relate to children and families with children. At the first meeting the committee asserted that our society had the potential to build child care and health services as good as any in the world; but to attain that objective we will need to give a higher priority to improvements in these services. The new committee will welcome advice from all statutory and voluntary agencies and from individuals, and intends to find out both why services are working well in some areas and why they are less successful in others. Then it plans to use its power of direct access to the Secretaries of State to press for practical measures and to influence public opinion.

With these fine sentiments the Children's Joint Committee has been given three years in the first instance to justify its existence. At least one facet of the Court Report has been implemented. We wish the committee success.

${ }^{1}$ Committee on Child Health Services, Fit for the Future, volumes 1 and 2. London, HMSO, 1976. (Court Report.)

\section{Behçet's disease}

For a disease of such rarity Behçet's disease enters into differential diagnosis quite often. In part this is because it may attack so many different organs: any combination of bizarre symptoms and signs together with mouth or genital ulcers should bring Behçet's disease to mind. Even so, it is rare for a doctor practising in Britain to diagnose more than one case in a lifetime. Rheumatologists perhaps see more than their fair share-largely because any puzzling disorder with ocular lesions and associated with joint disease gravitates towards them.

The classical triad of relapsing iritis with ulcers of the mouth and genitalia named after Behçet ${ }^{1}$ was first described by Blüthe in 1908." Since then, additional features have been described and shown to be clearly included in the variable pattern of the disease. In a recent series of 41 patients $^{3}$ the main site was the eye in 10 patients, the joints in eight, phlebitis often affecting the venae cavae in eight, and mucocutaneous or mucous lesions in nine; while neurological defects were the predominant manifestation in six patients, and erythema nodosum in one. This catalogue of systems was reflected in the clinics at which these patients were first seen: ophthalmological in 11 ; medical in 10; dermatological in nine; neurological and vascular three each; oral two; and gynaecological, urological, and ear, nose, and throat one each. The diagnostic clue was provided by oral ulceration, which was the earliest manifestation in 30 cases, was the presenting feature in 11 , and occurred at some time in all but one. Genital ulceration occurred in 36 of the 41 patients. Another classical diagnostic clue, blister formation or an inflammatory reaction at a venepuncture or scratch site, occurred in only 15.

Behçet's syndrome relies on suspicion and clinical acumen alone for diagnosis, but a novel approach has come from Leeds. ${ }^{+}$Behçet's disease, together with Whipple's disease, has been firmly placed in the group of spondarthroses" seronegative for rheumatoid factor on account of the linking or overlap of its principal features (peripheral joint lesions, sacroileitis, buccal ulceration, erythema nodosum, and thrombophlebitis) with other more established members of this group, including ulcerative colitis, Crohn's disease, ankylosing spondylitis, psoriatic arthritis, and Reiter's disease. Familial associations of the more common diseases in this group are now well recognised, suggesting a genetic component; but Behçet's and Whipple's diseases are so rare that no such association has yet become apparent.

Chamberlain ${ }^{4}$ did a survey in Yorkshire looking for cases of Behçet's disease with the help of general practitioners and hospitals and learnt of 41 cases in a population of five million. Of the 33 patients seen, 32 fulfilled her diagnostic criteria. The survey might have been expected to yield some cases with a more benign pattern: in fact, it confirmed the potential serious nature of the disease. Symptoms developed almost always between the ages of 15 to 40 . One patient died with lesions affecting the central nervous system. Ocular damage was milder in the Yorkshire patients than in those studied in the Levant, where posterior segment lesions caused total loss of vision, usually in both eyes, in eight of 41 patients. $^{3}$

Clues to aetiology are few and far between. Reports of clustering, particularly from Turkey and Japan, suggest the relevance of infective or environmental factors; while studies from Israel, where the disease occurs (along with multiple sclerosis) more commonly in immigrants than in the same groups in their countries of origin, are against a heritable disease of low penetrance. ${ }^{3}$ At a recent symposium on Behçet's disease in Istanbul environmental pollutants such as organochlorine compounds, pesticides, and copper were put forward as aetiological factors or triggers; thus guinea pigs receiving these chemicals for a year had developed oral aphthae, pyoderma, and genital ulcers in contrast to controls. ${ }^{6}$ Some support for a genetic component, comparable with that clearly shown in ankylosing spondylitis, comes from the Leeds survey, in which a modestly increased frequency of HLA B5 and B27 was found, confirming a report of increased frequency of B5 in Japan.' HLA B5 also appears more frequently in those patients with uveitis and Behçet's disease. ${ }^{*}$

There has been little progress in the treatment of Behçet's disease. Topical corticosteroids may be of value in the eye and mouth, while systemic corticosteroids, immunomodulatory drugs such as levamisole and penicillamine, and immunosuppressive drugs have also been claimed to be of benefit. Transfer factor was once thought to be of value, but the results of a recent controlled study have failed to confirm this. On the whole, the rarity of the disease means that most treatment will be empirical.

${ }^{1}$ Behçet, H, Dermatologische Wochenschrift, 1937, 105, 1152.

2 Blüthe, L, Inaugural Thesis, Heidelberg 1908.

${ }^{3}$ Chajek, T, and Fainaru, M, Medicine (Baltimore), 1975, 54, 179.

${ }^{4}$ Chamberlain, M A, Annals of the Rheumatic Diseases, 1977, 36, 491.

${ }^{5}$ Moll, J M H, et al, Medicine (Baltimore), 1974, 53, 343.

${ }_{6}^{6}$ Ishikawa, S, International Symposium on Behçet's Disease, Istanbul, 1977.

${ }^{7}$ Ohno, S, et al, Lancet, 1973, 2, 1383.

${ }^{8}$ Hamza, M, International Symposium on Behçet's Disease, Istanbul, 1977. 